\title{
Evaluation of Adsorption Capacity of Methylene Blue in Aqueous Medium by Two Adsorbents: The Raw Hull of Lophira Lanceolata and Its Activated Carbon
}

\author{
Elie Sogbochi ${ }^{1}$, Clément Kolawolé Balogoun ${ }^{1,2}$, Cocou Pascal Agbangnan Dossa ${ }^{1}$, \\ Dominique Codjo Koko Sohounhloue ${ }^{1}$ \\ ${ }^{1}$ Laboratory of Study and Research in Applied Chemistry (LERCA), Polytechnic School of Abomey-Calavi, University of Abomey-Calavi, \\ Cotonou, Republic of Benin \\ ${ }^{2}$ National Water Company of Benin, Cotonou, Republic of Bénin
}

\section{Email address:}

csohoun@gmail.com (D.C.K. Sohounhloue)

\section{To cite this article:}

Elie Sogbochi, Clément Kolawolé Balogoun, Cocou Pascal Agbangnan Dossa, Dominique Codjo Koko Sohounhloue. Evaluation of Adsorption Capacity of Methylene Blue in Aqueous Medium by Two Adsorbents: The Raw Hull of Lophira Lanceolata and Its Activated Carbon. American Journal of Physical Chemistry. Vol. 6, No. 5, 2017, pp. 76-87. doi: 10.11648/j.ajpc.20170605.11

Received: September 20, 2017; Accepted: September 30, 2017; Published: November 10, 2017

\begin{abstract}
The purpose of this study is to evaluate the adsorption capacity of two adsorbents from the lignocellulosic residues of Lophira Lanceolata. The raw hull of Lophira Lanceolata and its activated carbon produced by chemical activation with orthophosphoric acid $\left(\mathrm{H}_{3} \mathrm{PO}_{4}\right)$ at $50 \%\left(\mathrm{Vacid} / \mathrm{V}_{\text {water }}\right)$ of the said hull. The ratio of impregnation to orthophosphoric acid used is 4.5 . Activation and carbonization were carried out at $400^{\circ} \mathrm{C}$. The physicochemical properties of the prepared activated carbon were determined and methylene blue adsorption tests were performed. On the basis of the results obtained, the iodine test revealed that the activated carbon produced had a microporosity of $646.81 \mathrm{mg} / \mathrm{g}$, a density of 0.3156 , a moisture content of less than $15 \%$ and ash content equal to $2 \%$. Regarding the adsorption, results showed that methylene blue (100 ppm) adsorbed more easily on the activated carbon produced than on the crude residues with respective contact time of 10 minutes and 40 minutes. The removal rate was of the order of $100 \%$ for the activated carbon and of $83.56 \%$ for the raw hulls. Furthermore, an influence of the mass of the support, of the initial concentration and of the $\mathrm{pH}$ on the kinetics and on the adsorption capacity was observed. Kinetics obeyed to the pseudo-second order model; the diffusion was intra-particular and the Freundlich and Langmuir models satisfactorily described the adsorption of methylene blue respectively on the crude residues and on the produced activated carbon.
\end{abstract}

Keywords: Adsorption, Activated Carbon, Lophira Lanceolata, Methylene Blue, Microporosity

\section{Introduction}

Each year, large quantities of by-products from agricultural exploitation are released into the environment. In addition, there are industrial releases loaded with synthetic dyes and chemicals that lead to the pollution and degradation of water resources [1]. These influence the $\mathrm{pH}$ of water and can lead to serious public health hazard (cholera, diarrhea, reprotoxic effects, blue disease in children and cancer risks. Consequently, research has been carried out to establish methods for water and wastewater treatment (2 to 3 references). Most of research work carried out mainly focuses on the combination of physical treatments (coagulation, flocculation etc.) and chemical (ozonation, chlorination tec.) [2]. But these methods are often secondary sources of pollution and prove to be too costly. Moreover, the most recent physical methods such as anodic oxidation and electroxidation require technical means such as highvoltages, which are too expensive. In view of these difficulties, it is necessary to find alternative methods which simultaneously solve the problems linked to the degradation of the environment and water quality. In this context, several studies have highlighted the adsorption capacities of industrial dyes as well as heavy metals in water by residues 
of coconut, wood, sunflower stems, sugar cane which have been shown to be effective when converted into actived carbons ( 2 to 4 references). Activated carbon is a polyvalent material commonly used as an adsorbent due to its internal and external surface, as well as its extremely high microporous volumes [3]. It is also endowed with high adsorption capacities, fast adsorption kinetics, and relative ease of regeneration (references). Because of these properties, it arouses great covetousness in many fields (water treatment, manufacture of gas masks, etc). Precursors of activated carbon generally come from two sources: fossil (lignite, peat and coal) and vegetal. In order to reduce the cost of production of this material, research is now oriented towards agricultural lignocellulosic raw materials or from their processing industries. accordingly, previous research work in our laboratory has indicated that the fruits of Lophira Lanceolata release $33 \%$ of hulls that are rich in lignins (30\%) and can be used for the depollution of wastewater by adsorption of micropollutants [4]. On this basis, the general objective of this work aims at to making a comparative study of the capacity of eliminatiing methylene blue by the hull of Lophira Lanceolata and its actived carbon. Specifically, it was:

- to evaluate the adsorption kinetics of methylene blue on the crude residues and on the activated carbon of the shells of Lophira Lanceolata.

- to elucidate the process of adsorption by adsorption isotherms of the dye by the residues and by the activated carbon.

\section{Materials and Methods}

\subsection{Vegetal Material and Conditioning}

Lophira Lanceolata fruits were harvested in Boribansifa, in the commune of Toucountouna, in the North-West of Benin. They were sorted, separated in order to remove the allogenic material and then shelled; the hull obtained were grinded and then sieved (mesh size of $1.18 \mathrm{~mm}$ ). The grinded hull of Lophira Lanceolata obtained were washed with tap water, rinsed with distilled water and then dried in an oven at $110^{\circ} \mathrm{C}$ for 24 hours. After drying process, the latter were stored at room temperature in the laboratory for adsorption tests and for activated carbon preparation.

\subsection{Swelling Test}

The swelling test was performed by taking $11 \mathrm{~mL}$ of powdered material which was completed with water to obtain a total volume of $20 \mathrm{~mL}$. 24 hours later the volume of the powdered material was raised.

\subsection{Methodology for the Production and Characterization of Activated Carbon}

The preparation of the activated carbon can be carried out from any precursor containing carbon. The precursor used in this study was the hull of Lophira Lanceolata. Activated carbon, after production, was used to remove methylene blue in an aqueous medium.

\subsubsection{Production of Activated Carbon}

Activated carbon was prepared from the hull of Lophira Lanceolata in four stages: pretreatment, chemical activation, pyrolysis and washing (Balogoun and al., 2015).

\subsubsection{Treatment with Orthophosphoric Acid $\left(\mathrm{H}_{3} \mathrm{PO}_{4}\right)$}

The grinded hull of Lophira Lanceolata were impregnated with orthophosphoric acid diluted to $50 \%\left(\mathrm{H}_{3} \mathrm{PO}_{4} / \mathrm{H}_{2} \mathrm{O}\right.$ : V/V) with an impregnation ratio (RI) of 4.5 .

$$
\mathrm{RI}=\frac{m_{\mathrm{H}_{3} \mathrm{PO}_{4}}}{\text { mprecursor }}
$$

The mass of the precursor was that of the pretreated biomass. At the end of this impregnation operation, the mixtures (hull + $\mathrm{H}_{3} \mathrm{PO}_{4}$ solution) was dried at $110^{\circ} \mathrm{C}$. In a Leader Engineering Widnes Cheshire UK for at least 24h [5, 8].

\subsubsection{Carbonisation of Activated Carbon Precursors}

The carbonization was carried out in a furnace $\left(400^{\circ} \mathrm{C}\right)$ programmed at a temperature gradient of $10^{\circ} \mathrm{C} / \mathrm{min}$. After a stay of $2 \mathrm{~h}$ at the final temperature $\left(400^{\circ} \mathrm{C}\right)$, the activated carbon obtained was removed from the furnace and then cooled in a desiccator, this method is similar to that of Balogoun and al. (2015) [5].

\subsubsection{Washing of Activated Carbon}

The prepared activated carbon was washed with an amount of hydrochloric acid solution and then distilled water. In each case, the experiment was held in a water bath (warm water for no more than 24 hours) before the solution or washing water was renewed continuously for at least two months. This operation made it possible to reorganize the sheets of the activated carbon and to remove residues of the activating agent which clogs the pores. After washing, the activated carbon was dried at a temperature of $110^{\circ} \mathrm{C}$. Until a dry activated carbon was obtained [5].

\subsection{Some Physicochemical Properties of Activated Carbon}

\subsubsection{Determination of the Mass Yield}

The yield $\mathrm{r}$ of the prepared activated carbon was estimated from the following equation [5]:

$$
r=\frac{\text { mass of activeted carbon }(\mathrm{g})}{\text { mass of impregnated crushed hull }(\mathrm{g})} * 100
$$

\subsubsection{Determination of Iodine Value}

The iodine value of the produced activated carbon was determined using the American Society for Testing and Materials D4607-94 (ASTM D4607-94, 2006). The amount of iodine adsorbed (mg) per gram of activated carbon with a residual iodine concentration of $0.02 \mathrm{~N}$, represented the iodine value [6]. The titration with sodium thiosulphate of a volume $\mathrm{Vf}=25 \mathrm{~mL}$ of the filtrate made it possible to demonstrate the capacity of adsorption of iodine by the activated carbon. The equation of the reaction is as follows:

$$
\mathrm{I}_{2}+2 \mathrm{~S}_{2} \mathrm{O}_{3}^{2-} \rightarrow \mathrm{S}_{4} \mathrm{O}_{6}^{2-}+\mathrm{I}^{-}
$$


From the stoichiometric relationship of the reaction equation between iodine and sodium thiosulphate, the amount of iodine adsorbed by the activated carbon is deduced. Let $\mathrm{X}^{\prime}$ be the quantity of iodine adsorbed:

$\mathrm{X}^{\prime}=$ amount of initial iodine - amount of iodine remaining after $30 \mathrm{~s}$ of contact. The amount of residual iodine is determined by the relationship:

$$
X^{\prime}=V_{1} N_{1}-\frac{\left(V_{1}+V_{H C l}\right) N_{2} V_{t h}}{V_{f}}
$$

With:

$\mathrm{N}_{1}=0.1 \mathrm{~N}$ normality of the iodine solution; $\mathrm{N}_{2}=0.1 \mathrm{~N}$ normality of the sodium thiosulfate solution; $\mathrm{V}_{1}=50 \mathrm{~mL}$ the volume of iodine treated; $\mathrm{V}_{\mathrm{HCl}}=5 \mathrm{~mL}$; Volume of hydrochloric acid; $\mathrm{V}_{\mathrm{f}}=25 \mathrm{~mL}$ the volume of iodine titrated.

The iodine value of the activated carbon is then calculated using the equation of the curve

$$
\frac{X}{m}=f(C r)
$$

With: $\mathrm{m}$ the mass $(\mathrm{g})$ of activated carbon; $\mathrm{Cr}$ concentration of residual iodine

$\mathrm{X}$ is the quantity in $\mathrm{mg}$ of adsorbed iodine given by the relationship:

$$
\mathrm{X}(\mathrm{mg})=126.90 . \mathrm{X}^{\prime} .
$$

\subsubsection{Determination of Density}

To determine the density we weighed mass a $\mathrm{m}$ of a volume of $50 \mathrm{~mL}$ of activated carbon; The equivalent mass $\mathrm{m}_{0}$ of the same volume of $50 \mathrm{~mL}$ of the distilled water was also weighed; then, the calculation of the density was done by the relation:

$$
d=\frac{m}{m_{0}}
$$

\subsubsection{Determination of Ash Rate}

The ash rate $(\% \mathrm{C})$ was calculated as follows [7]:

$$
\% \mathrm{C}=\frac{\mathrm{m}_{3}-\mathrm{m}_{2}}{\mathrm{~m}_{1}} * 100
$$

$\mathrm{m}_{1}$ : initial mass of the AC used in $(\mathrm{g})$.

$\mathrm{m}_{2}$ : mass of the crucible before carbonization in $(\mathrm{g})$.

$\mathrm{m}_{3}$ : mass of the crucible filled after charring in $(\mathrm{g})$.

\subsubsection{Determination of Moisture Content}

The moisture content $(\% \mathrm{H})$ can be calculated by the following formula [7]:

$$
\% \mathrm{H}=\frac{\mathrm{m}_{3}-\mathrm{m}_{2}}{\mathrm{~m}_{1}}
$$

$\mathrm{m}_{1}$ : initial mass of the $\mathrm{AC}$ used in $(\mathrm{g})$.

$\mathrm{m}_{2}$ : mass of the crucible filled after drying $(\mathrm{g})$.

$\mathrm{m}_{3}$ : mass of the crucible filled before drying $(\mathrm{g})$.

\subsection{Methodology of Adsorption Tests}

\subsubsection{Kinetic Study of Adsorption: Contact Time}

Adsorption kinetics were studied to determine the amount of dye adsorbed at different time intervals (equilibrium time is one of the most economically important factors for polluted water treatment systems) [8]. A volume of $200 \mathrm{~mL}$ of dye-laden solution (methylene blue) of the concentration of $100 \mathrm{ppm}$ was stirred at $200 \mathrm{rpm}$. $2 \mathrm{~mL}$ samples were collected at intervals of time ( 5 min for crude residues and 1 min for activated carbon) are filtered on Wattman filter papers $\mathrm{N}^{\circ} 1$ and analyzed by UV/visible absorption spectrophotometry. The residual concentration of the dye was determined by the Beer-Lambert law. The quantity Qt of the dye adsorbed at time $t$ is given by the equation:

$$
Q t=(C o-C e) \frac{m}{V}
$$

$\mathrm{Q}_{\mathrm{t}}$ : amount of adsorbed dye per gram of adsorbent $\left(\mathrm{mg} \cdot \mathrm{g}^{-1}\right)$;

$\mathrm{C}_{0}$ : initial dye concentration $\left(\mathrm{mg} . \mathrm{L}^{-1}\right)$;

$\mathrm{Ce}$ : residual concentration at equilibrium $\left(\mathrm{mg} . \mathrm{L}^{-1}\right)$;

$\mathrm{V}$ : volume of the solution (L);

$\mathrm{m}$ : mass of the adsorbent $(\mathrm{g})$.

\subsubsection{Influence of Some Parameters on Adsorption}

\section{i. Effect of Mass of Adsorbent}

This study consisted in following the effects of the mass of the adsorbents (the crude hull and the activated carbon) on the adsorption. To this end, we have introduced into several erlenmeyers variable masses of adsorbent, the same volume of pollutant solution at the same concentration and at free $\mathrm{pH}$. The whole was stirred under the same conditions for a period greater than or equal to that of the adsorption equilibrium and the residual concentration of the pollutant was determined. The mass effect was studied at room temperature, at a rate of $200 \mathrm{rpm}^{-1}$ and $100 \mathrm{ppm}$ of methylene blue. The chosen adsorbent masses vary between 0.1 and $2 \mathrm{~g}$.

\section{ii. Influence of $\mathrm{pH}$}

This consists in following the effects of $\mathrm{pH}$ on the various parameters of the adsorption. For this purpose, the same mass of adsorbent and the same volume $(2000 \mathrm{~mL})$ of pollutant solution of the same concentration, but whose $\mathrm{pH}$ values are variable ( $\mathrm{pH}$ varying from 2 to 12 ), have been introduced into several Erlenmeyer plants. The whole was stirred under the same conditions for a period longer than the equilibrium time previously determined. After the equilibrium time, the solutions containing the adsorbent were filtered and the residual pollutant and control concentrations were determined. The initial $\mathrm{pH}$ values of the dye solutions were adjusted using the $\mathrm{NaOH}(0.1 \mathrm{~N})$ and $\mathrm{HCl}(0.1 \mathrm{~N})$ solutions for the different $\mathrm{pH}$ values studied $(2 ; 4 ; 6 ; 8 ; 10 ; 12)$.

\section{iii. Influence of Initial Solution Concentration}

This study consisted in following the effects of the concentration on the various parameters of the adsorption. For this purpose, the same mass of adsorbent and the same volume $(50 \mathrm{~mL})$ of pollutant solution of variable concentrations and at free $\mathrm{pH}$ of the solution were introduced into several erlenmeyers. The whole was stirred under the same conditions for a period longer than the equilibrium time, we have filtered and the residual concentration of the 
pollutant was determined. The effect of the initial dye concentration was studied by stirring at a rate of $200 \mathrm{rpm}^{-1}$, $200 \mathrm{~mL}$ of dye solutions, the concentrations used varying from 5 to $150 \mathrm{ppm}$.

\subsubsection{Modeling of Adsorption Kinetics}

Several kinetic models have been used to interpret the experimental data to provide essential information for the use of these adsorbents in the adsorption domain. We adopted five (05) kinetic models that are: pseudo-first order (PPO), pseudo-second order (PSO) models, external diffusion, intraparticular scattering and Elovich model. $[9,10]$

\section{i. Pseudo First Order Model (PPO)}

The expression is given by Lagergren:

$$
\frac{d Q t}{d t}=\mathrm{k}_{1}(\mathrm{Qe}-\mathrm{Qt})
$$

$\mathrm{k}_{1}$ : first-order reaction rate constant of adsorption of the dye on the adsorbents $\left(\mathrm{min}^{-1}\right)$.

Qe: amount of the adsorbed dye at equilibrium in $\left(\mathrm{mg}^{\mathrm{g}} \mathrm{g}^{-1}\right)$.

Qt: amount of the dye adsorbed at time $t$ in $\left(\mathrm{mg} \mathrm{g}^{-1}\right)$.

$\mathrm{t}$ : contact time in (min).

After integration with the initial conditions $q \mathrm{t}=0$ to $\mathrm{t}=0$, the equation becomes:

$$
\mathrm{Qt}=\mathrm{Qe}\left(1-\mathrm{e}^{-\mathrm{k} 1 \mathrm{t}}\right)
$$

The linearization of the preceding equation gives:

$$
\ln \left(\mathrm{Q}_{\mathrm{e}}-\mathrm{Q}_{\mathrm{t}}\right)=\ln \mathrm{Q}_{\mathrm{e}}-\mathrm{k}_{1} \mathrm{t}
$$

One plots $\ln (\mathrm{Qe}-\mathrm{Qt})=\mathrm{f}(\mathrm{t})$, we obtain a straight line which gives $\mathrm{k}_{1}$ and $\mathrm{Qe}$.

This model makes it possible to describe the phenomena occurring during the first minutes of the adsorption process [11].

\section{ii. Pseudo-second Order Model (PSO)}

The pseudo-second order model (PSO) is given by the following expression:

$$
\frac{d Q t}{d t}=\mathrm{k}_{2}\left(\mathrm{Q}_{\mathrm{e}}-\mathrm{Q}_{\mathrm{t}}\right)^{2}
$$

where:

$\mathrm{K}_{2}$ : Second order reaction rate of adsorption of the dye on the adsorbents in $\left(\mathrm{g} \cdot \mathrm{mg}^{-1} \cdot \mathrm{min}^{-1}\right)$.

$Q_{e}^{2}$ : amount adsorbed at equilibrium in $\left(\mathrm{mg} \mathrm{g}^{-1}\right)$,

Qt: amount adsorbed at time $\mathrm{t}$ in $\left(\mathrm{mg}^{\mathrm{g}} \mathrm{g}^{-1}\right)$.

$\mathrm{t}$ : contact time ( $\mathrm{min})$.

After integration, we obtain:

$$
Q_{t}=\frac{\mathrm{K}_{2} * \mathrm{Qt}}{1+\mathrm{K}_{2} * \mathrm{Q}_{\mathrm{e}} * \mathrm{t}}
$$

The linearization of the preceding equation gives:

$\mathrm{h}=\mathrm{k}_{2} \mathrm{Q}_{\mathrm{e}}{ }^{2}$ is the initial adsorption rate in $\left(\mathrm{mg}^{-1}\right.$. min).

We trace $t / Q t=f(t)$, we get a straight line which gives $k_{2}$ and Qe.

Unlike the first-order model, the pseudo-second order model is applicable to a wider time interval (generally the entire adsorption process)

\section{iii. External Delivery Model}

The external diffusion, through the film surrounding the solid particles of the adsorbent. A model of this phenomenon is represented by the equation:

$$
\operatorname{Ln}[(\mathrm{Co}-\mathrm{Ce}) /(\mathrm{C}-\mathrm{Ce})]=\mathrm{K}_{3} \times \mathrm{t}
$$

Where $\mathrm{K}_{3}$ is the external diffusion constant, Co, Ce and $\mathrm{C}$, the initial concentrations in ppm, at equilibrium then at time $\mathrm{t}$ (min), respectively.

\section{iv. Intraparticular Scattering Model}

The molecules are probably transported in the particles of the adsorbents by an intraparticular diffusion process because of the porosity of the adsorbents. Generally three steps are involved during the adsorption process by the porous adsorbent: i) transfer of the molecule adsorbed from the breast of the solution to the external surface of the adsorbent (external diffusion), ii) penetration of the adsorbed molecule to Adsorption of the molecule on the inner surface of pores [12]. To understand the mechanism of adsorption of the two dyes we use the equation of Weber et al. (1963) [13]:

$$
\mathrm{Q}_{\mathrm{t}}=\mathrm{k}_{\mathrm{i}} * \mathrm{t}^{1 / 2}+\mathrm{c}
$$

Qt: this is the quantity adsorbed at time $\mathrm{t}\left(\mathrm{mg} \cdot \mathrm{g}^{-1}\right)$,

c: the intersection of the line with the $\mathrm{Y}$ axis or the intercept.

\section{v. Model of Elovich}

It can be expressed as:

$$
\frac{d Q t}{d t}=\alpha \exp (-\beta Q t)
$$

Where: $\alpha$ : the initial rate of adsorption $\left(\mathrm{mg} \cdot \mathrm{g}^{-1}\right.$. Min) and $\beta$ : the desorption constant $\left(\mathrm{g} \cdot \mathrm{mg}^{-1}\right)$.

To simplify the Elovich equation it has been assumed that $\alpha \beta \mathrm{t}>1$ and that

$\mathrm{Qt}=0$ to $\mathrm{t}=0$, so we get:

$$
Q_{t}=\frac{1}{\beta} \ln (\alpha \boldsymbol{\beta})+\frac{1}{\beta} \operatorname{lnt}
$$

We trace $Q_{t}=f(\ln t)$

The values of $\alpha$ and $\beta$ can be determined $[14,15]$.

\subsubsection{Modeling Adsorption Isotherms}

We have described the adsorption process using two adsorption isotherms: the linear Langmuir and Freundlich transforms. The isotherm is the curve which represents the relationship between the quantity of methylene blue adsorbed per unit mass of adsorbent Qe and the concentration of solute in solution $\mathrm{Ce}$. We obtained such curves from the results of laboratory tests carried out at $25^{\circ} \mathrm{C}$. To this end, known quantities of adsorbent are introduced into volumes of water to be treated and, after a given contact time, the residual concentration of solute in solution is measured. The amount of adsorbed solute is calculated using the equation: 


$$
\mathrm{Q}_{\mathrm{e}}=\frac{\left(\mathrm{C}_{0}-\mathrm{Ce}\right) * \mathrm{~V}}{\mathrm{~m}}
$$

\section{i. Langmuir Isotherm}

This model corresponds to the L-type isotherms (Langmuir, 1918 quoted by Voice \& Weber (1983) [18]:

$$
Q_{e}=\frac{Q_{\max } * k_{L} * C_{e}}{1+k_{L} * \mathrm{C}_{\mathrm{e}}}
$$

Qe: Content in the adsorbent at equilibrium ( $\mathrm{M}$ of soil pollutant. $\mathrm{M}^{-1}$ ),

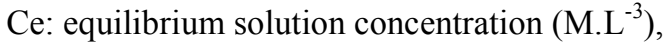

$\mathrm{Q}_{\max }$ : Maximum content in the adsorbent (M.M-1 of sol),

$\mathrm{K}_{\mathrm{L}}$ : Langmuir Constant $\left(\mathrm{L}^{3} \cdot \mathrm{M}^{-1}\right.$ of pollutant $)$

\section{ii. Freundlich's Isotherm}

This model establishes a relation between the quantity of impurity (methylene blue) adsorbed and the quantity remaining in the liquid phase, this equation is based on an exponential distribution of the energies of the adsorption sites, it is expressed by the following relation [17]

$$
\mathrm{Qe}=\mathrm{KC}_{\mathrm{e}}{ }^{1 / \mathrm{n}}
$$

Equation which is linearized in the following form:

$$
\log Q_{e}=\log K+1 / n \log C e .
$$

Qe: Amount of adsorbed impurity per unit mass of adsorbent (mg.g $\left.\mathrm{g}^{-1}\right)$

Ce: residual concentration of the adsorbate at equilibrium (mg.L ${ }^{-1}$ )

$\mathrm{K}$, n: Freundlich constants of the pollutant

It is a line of slope $1 / \mathrm{n}$ and of ordered at the origin $\log \mathrm{K}$. High values of $K$ and $n$ indicate a strong adsorption in the range of the studied concentrations. Conversely, low values indicate low adsorption at low solute concentrations. This equation differs from the previous one by the fact that it does not provide for an upper limit to adsorption and that it admits the possibility of interaction between adsorbed particles. The parameters $\mathrm{K}$ and $1 / \mathrm{n}$ specific of the pollutant-material torques are of importance in the comparison of the performances of the materials.

The $\mathrm{k}_{\mathrm{F}}, \mathrm{k}_{\mathrm{L}}, \mathrm{R}_{\mathrm{L}}, \mathrm{Q}_{\max }$ and $\mathrm{n}$ parameters characterizing the Langmuir and Freundlich models for the adsorption of methylene blue on activated carbon and crude residues were determined from the slopes and ordinates at the origin Linear transformations of Freundlich and Langmuir.

\section{Results and Discussion}

\subsection{Swelling Test}

After 24 hours in the water, no significant change in the volume of the powdered product was observed. We therefore continued the test over a period of 48 hours and then 72 hours. We found that the initial volume of powder had not undergone any variation. This insensitivity to water would be due to its chemical composition more precisely in lignin. Indeed, lignin is known to provide vascular plants with rigidity and waterproofness, as well as high resistance to decomposition. It can therefore be deduced that this material cannot be used as a filter bed.

\subsection{Production Yield and Physical-chemical Characteristics of Activated Carbon}

\subsubsection{Production Efficiency}

The production yield of activated carbon is an important parameter in the feasibility study of the production of activated carbon from a given precursor and under specified conditions. It is one of the performance indicators of a method of preparing this material for industrial production. The production yield of the activated carbon was $75.17 \%$.

\subsubsection{Physico-chemical Characteristics of Activated Carbons}

\section{i. Ash Content}

The ash content obtained is equal to $2 \%$ and is therefore very low. According to some authors, the lower the ash rate, the better the active carbon (at least 2 references).

\section{ii. Density}

This is the density of activated carbon for a densified bed, for gas storage applications, activated carbon is often densified to obtain more storage capacity in the same volume. The density of the produced activated carbon is 0.3156 .

\section{iii. Moisture Content}

We assessed the amount of water physically linked to activated carbon by determining the moisture content. The value obtained in this study for our material was less than $15 \%$ by weight.

\section{iv. Indice of Iodine}

It has been reported by numerous groups of researchers [18] that the iodine value is an indication of the adsorption capacity in micropores. There is therefore a proven correlation between the iodine value and the specific surface area. The isotherm of adsorption of iodine by activated carbon:

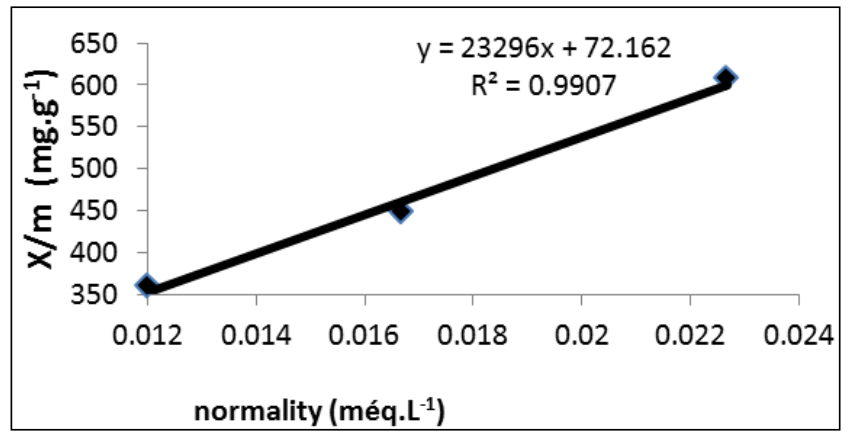

Figure 1. Isotherm of Adsorption of Iodine by Activated Carbon.

It is deduced that indice of iodine value of activated carbon was $646.81 \mathrm{mg} \cdot \mathrm{g}^{-1}$. 


\subsection{Spectrophotometric Properties of Methylene Blue}

\subsubsection{Determination of the Maximum Absorption Wavelength}

The analysis of the dye studied was carried out by spectrophotometry in the visible range (380 -750 nm). When determining the absorbance of methylene blue as a function of wavelength, a peak was observed at a wavelength between $660 \mathrm{~nm}$ and $670 \mathrm{~nm}$ (Figure 2). We have therefore chosen as the maximum absorption wavelength $(\lambda \max ) 665 \mathrm{~nm}$ to perform the spectrophotometric analyzes of the solutions of methylene blue.

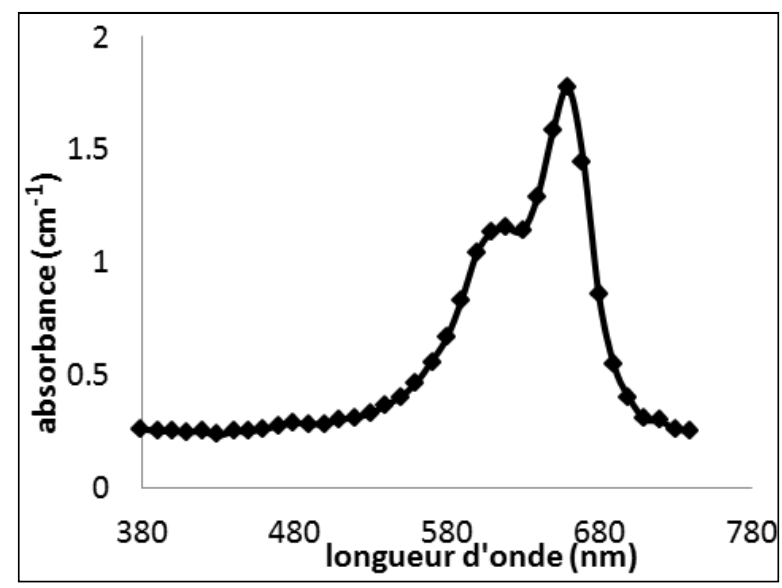

Figure 2. Absorption Curve of Methylene Blue as a Function of Wavelength.

\subsubsection{Verification of the Beer Lambert Law by the Plot of the Calibration Curve}

The calibration curve is established from the diluted solutions of methylene blue, Figure 3 showed that the line has a regression coefficient $\left(\mathrm{R}^{2}=0.9998\right)$ which is very close to unity. Thus, there is a possibility of determining the residual concentrations by the Beer-Lambert law. The absorbance is proportional to the concentration. However, it should be noted that concentrations of the methylene blue solution were taken between $0 \mathrm{ppm}$ and $600 \mathrm{ppm}$. Concentrations greater than $45 \mathrm{ppm}$ were diluted to remain within the detection limit of the apparatus. The actual values were determined by multiplying the obtained absorbances by the dilution factors.

$$
\text { Absorbance }=0.016 * \mathrm{C}
$$

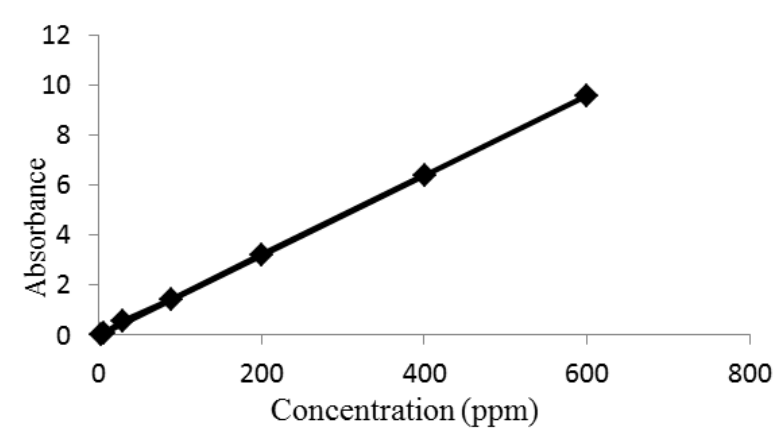

Figure 3. Calibration Curve of the Absorption of Methylene Blue in Aqueous Solution at $25^{\circ} \mathrm{C}$.

\subsection{Adsorption Tests}

\subsubsection{Evaluation of the Adsorption Capacity of Methylene Blue by the Residues of the Hulls of Lophira Lanceolata}

In our study, we investigated the adsorption of methylene blue on the hull grinded of Lophira Lanceolata, which is a natural adsorbent available in both northern and central Benin. This adsorbent was used in the raw state without prior treatment; The preparation of the sample and the adsorption procedure have already been described previously. In order to optimize the adsorptive power of this material, various parameters were studied: the mass of the adsorbent, the contact time, the initial dye concentration and the $\mathrm{pH}$.

\section{i. Study of the Parameters Influencing Adsorption}

Effect of mass of adsorbent (figure 4) showed that the amount of adsorbed methylene blue increases as the mass of the adsorbent increases. According to Hameed (2010) [19], this was explained by the increase in the number of adsorption sites. The maximum elimination rate recorded is $83.56 \%$ for a mass greater than or equal to $1 \mathrm{~g}$.

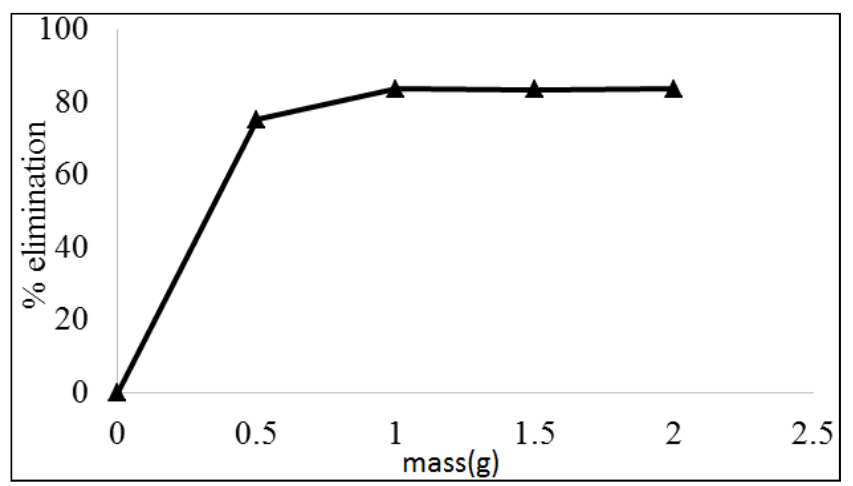

Figure 4. Evolution of the Rate of Removal of Methylene Blue as a Function of the Mass of the Grinded huLls.

Operating conditions: Temperature $=25^{\circ} \mathrm{C}$, stirring speed $=200 \mathrm{rpm}$ and mass $=1 \mathrm{~g}$.

At the concentration of $100 \mathrm{mg} . \mathrm{L}^{-1}$ of methylene blue, the maximum elimination rate recorded was $83.56 \%$ for a mass equal to 1 gram. Above $1 \mathrm{~g}$ of grinded material, the removal rate becomes constant. The increase in the reduction rate of methylene blue with the increase of the adsorbent mass is due to the availability of a large active surface area. On the other hand, the constancy in the dye removal rate for a mass greater than 1 gram is due to the bulkiness of the solution by the ground media which prevent the molecules of methylene blue from accessing the active sites. As reported by Mane and al. (2007) and Hui and al. (2011) [20, 21].

\section{ii. Effect of Contact Time}

The adsorption kinetics studied revealed that the equilibrium was reached after $40 \mathrm{~min}$ and the maximum removal rate was $83.56 \%$. It was observed that the adsorption is rapid during the first 30 minutes of the reaction

(Figure 5). For high contact times, the molecule needs time to 
reach new adsorption sites, Sahnoun (2011) [22] drew the same conclusion. The remainder of the unadsorbed amount is explained by the saturation of the surface of the adsorbent.

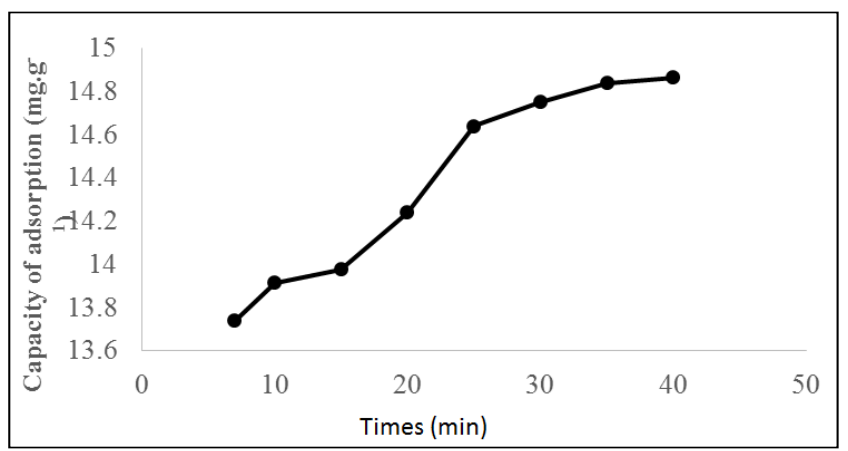

Figure 5. Adsorption Kinetics of the BM on the Grinded Hulls.

Operating conditions: Temperature $=25^{\circ} \mathrm{C}$, stirring speed $=200 \mathrm{rpm}$, and mass $=1 \mathrm{~g}$.

\section{iii. Effect of pH}

According to Figure 6, the adsorption capacity increases slightly as the $\mathrm{pH}$ of the solution increases. According to Nonviho (2015) [4], the hulls of Lophira Lanceolata contain Cellulose and hemicellulose (hydroxide groups or oxides), which charge negatively in aqueous media. Thus the increase in $\mathrm{pH}$ favors the development of the negative electrical charge of the surface. This negative charge exhibits an electrostatic attraction with respect to the cationic dye (methylene blue).

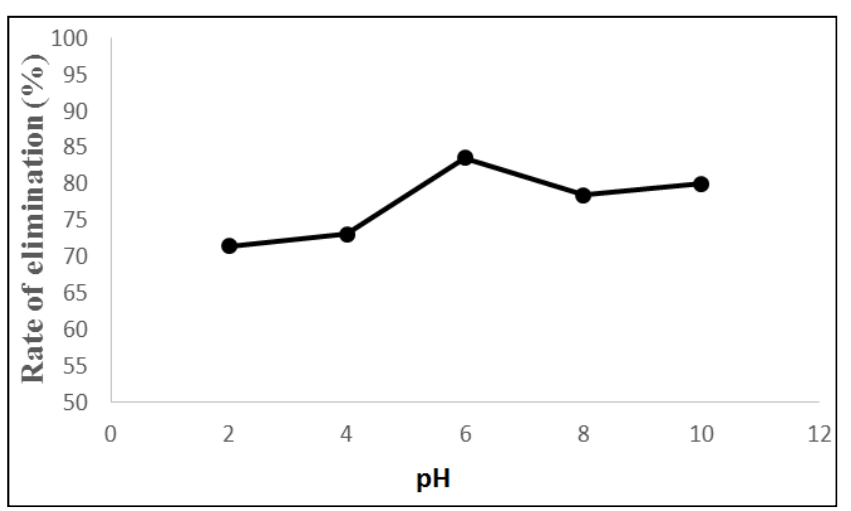

Figure 6. Effect of pH on the Adsorption of bm on Grinded Hulls.

Operating conditions: Temperature $=25^{\circ} \mathrm{C}$, stirring speed $=200 \mathrm{rpm}$ and Volume of the methylene blue solution $=200 \mathrm{~mL}$.

\section{iv. Effect of Initial Concentration of Methylene Blue}

The adsorption of methylene blue onto the hulls of Lophira Lanceolata was carried out at different initial dye concentrations (25 ppm, $50 \mathrm{ppm}, 75 \mathrm{ppm}, 100 \mathrm{ppm} 150$ $\mathrm{ppm}$ ). The analysis of these results (Figures 8 and 9) revealed that, whatever the initial concentration of methylene blue, the adsorption capacity reached its maximum after 10 minutes.

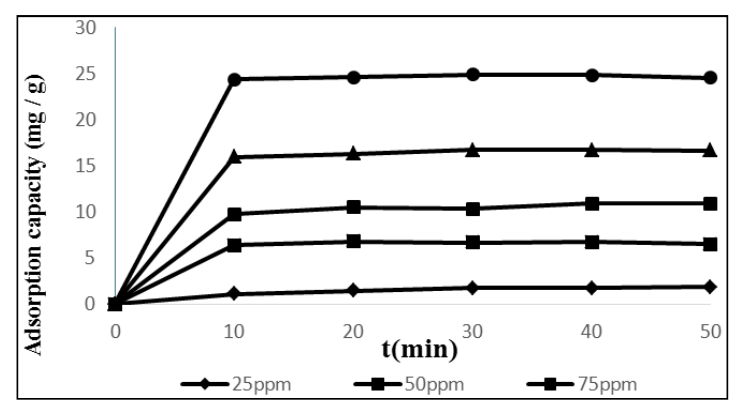

Figure 7. Influence of the Initial Concentration on the Adsorption Capacity of BM on Grinded Hulls.

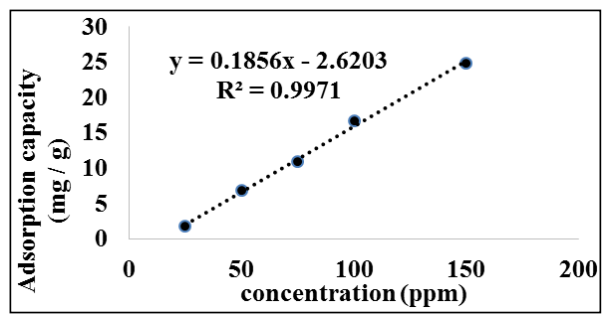

Operating conditions: Temperature $=25^{\circ} \mathrm{C}$, stirring speed $=200 \mathrm{rpm}$ and mass $=1 \mathrm{~g}$.

Figure 8. Influence of the Concentration on the Adsorption Capacity of the BM on Grinded Hulls.

The graph plots showing the influence of the concentration on the absorption capacity (Figures 7 and 8 ) revealed that the amount of methylene blue adsorbed increased with the initial concentration. Indeed, the increase in the concentration of methylene blue accelerates the diffusion of the latter due to the increase in attraction forces of the concentration gradient [23]. Note the formation of bearings, which indicates a rapid saturation of the support following better diffusion of molecules of methylene blue to the adsorption sites which are still free.

\subsubsection{Modeling of Adsorption Kinetics}

\section{i. Pseudo First Order (PPO) and Pseudo-second Order (PSO)}

Two kinetic models have been applied to the experimental data to understand the mechanism of this discoloration (Figures 9 and 10).

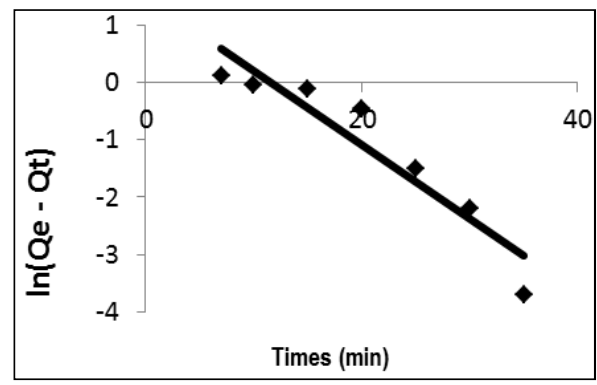

Figure 9. Pseudo-first Order Kinetics. 


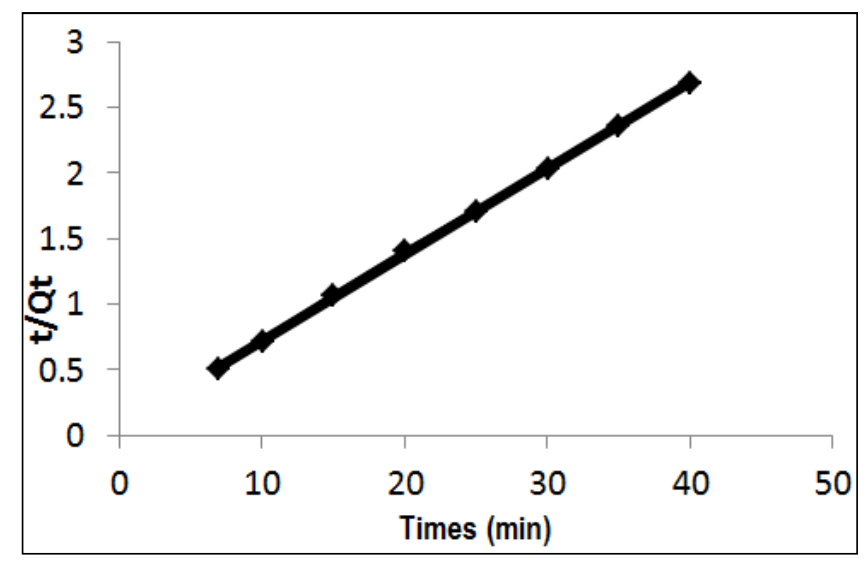

Figure 10. Second-order Pseudo Kinetics.

Table 1. Adsorption Kinetic Parameters.

\begin{tabular}{|c|c|c|c|}
\hline Equation & $\mathbf{R}^{2}$ & $K_{1}(\min -1)$ & $Q_{\mathrm{e}}\left(\mathrm{mg} \cdot \mathrm{g}^{-1}\right)$ \\
\hline \multicolumn{4}{|c|}{ Pseudo-first order kinetics } \\
\hline$y=-0.1287 x+1,4838$ & 0.8904 & 0.1287 & 30.4649 \\
\hline Equation & $\mathbf{R}^{2}$ & $K_{2}$ (g/mg.min) & $Q_{e}\left(m g . g^{-1}\right)$ \\
\hline \multicolumn{4}{|c|}{ Second-order pseudo kinetics } \\
\hline$y=0.0656 x+0.0694$ & 0.9997 & 16.1269 & 15.2439 \\
\hline
\end{tabular}

From Table 1, it can be seen that the set of kinetic parameters determined from the two previous straight make it possible to deduce the kinetic model of discoloration. The correlation coefficient $\left(\mathrm{R}^{2}\right)$ for the second-order model was closer to 1 (i.e 0.9997) than that of the first-order model (0.8904). The second-order model thus gives a better description of the adsorption kinetics compared to the firstorder kinetics. Indeed, the equilibrium adsorption capacity calculated using this model was also very close to that found experimentally. The adsorption of methylene blue was thus controlled by the chemical processes that involve the valence forces or the electron exchanges with the biosorbent. The same obsersavation has been previously made by Nonviho [4] with the same material and at the same concentration.

\section{ii. Type of Broadcast}

Table 2. Dissemination Parameters.

\begin{tabular}{|c|c|c|c|}
\hline \multirow{2}{*}{ Equation } & \multicolumn{3}{|c|}{ external diffusion } \\
\hline & $\mathbf{R}^{2}$ & \multicolumn{2}{|c|}{$\mathbf{K}_{3}$} \\
\hline$y=0.1777 x$ & 0.7328 & \multicolumn{2}{|c|}{0.1777} \\
\hline \multirow{2}{*}{ Equation } & \multicolumn{3}{|c|}{ Intra-particular diffusion } \\
\hline & $\mathbf{R}^{2}$ & $K_{4}$ & constant \\
\hline$y=0.34 x+12,802$ & 0.9556 & 0.34 & 12.802 \\
\hline \multirow{2}{*}{ Equation } & \multicolumn{3}{|c|}{ Elovich model } \\
\hline & $R^{2}$ & $\alpha$ & $\beta$ \\
\hline$y=0.7158 x+12.238$ & 0.9370 & 4552.76 & 1.40 \\
\hline
\end{tabular}

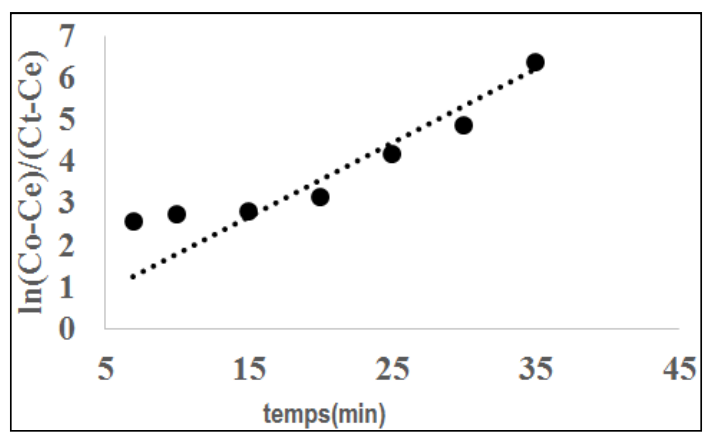

Figure 11. Kinetics of External Diffusion.

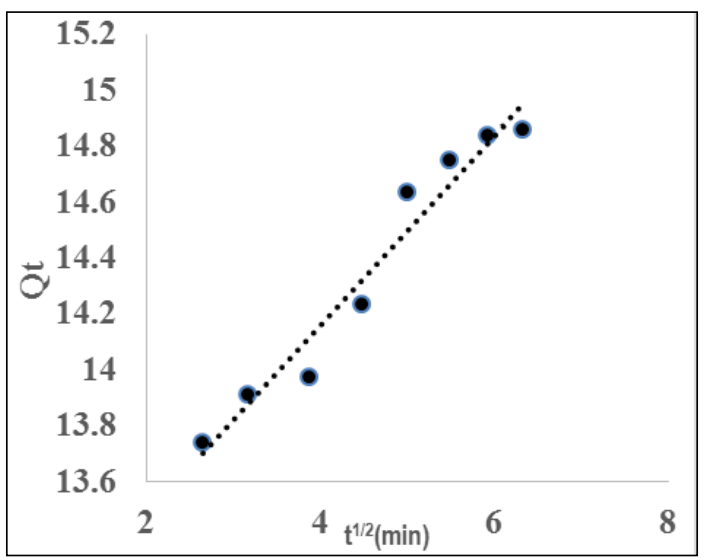

Figure 12. Kinetics Intraparticular Diffusion.

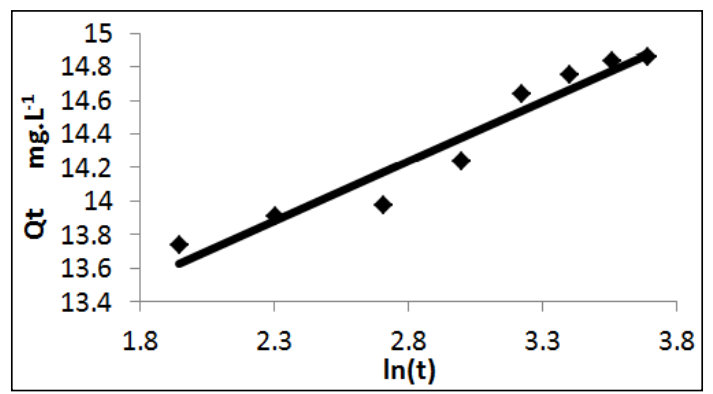

Figure 13. Elovich Model.

The intraparticular diffusion model has a better linearity compared to other models. Indeed, the linear correlation coefficient of the intraparticular model was closer to 1 than those of the other models. The adsorption of methylene blue on the raw hulls (CB) of Lophira Lanceolata follows the intraparticle model. It can therefore be deduced that there was formation of chemical bonds between the adsorption sites of the hulls of Lophira Lanceolata and the bis-(dimethylamino) 3,7 -phenazathionium ion of methylene blue [4].

\section{iii. Study of Adsorption Isotherms}

To describe the adsorption of the dye, the two most frequently used models were used: the models of Langmuir and of Freundlich. 


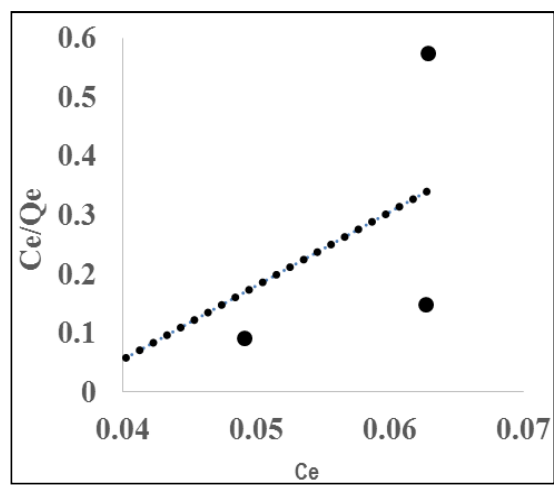

Figure 14. Langmuir Model.

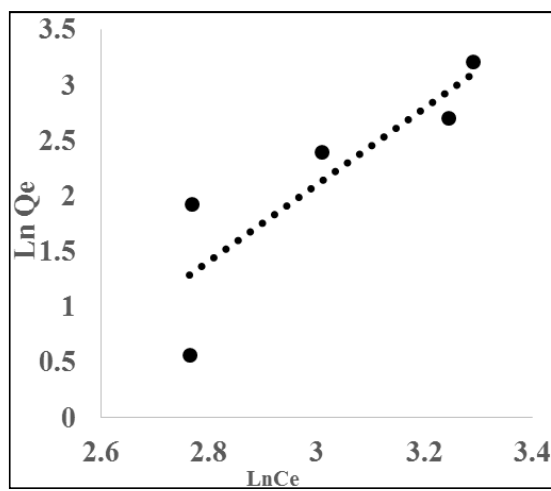

Figure 15. Freundlich Model.

Table 3. Characteristics of the Different Models.

\begin{tabular}{lllll}
\hline & Equation & $\mathbf{R}^{2}$ & Constants & \\
\hline Langmuir & $\mathrm{y}=12.557 \mathrm{x}-0.4471$ & 0.5015 & $\mathrm{Q}_{\max }=14.40 \mathrm{mg} / \mathrm{g}$ & $\mathrm{K}_{\mathrm{L}}=-0.155 \mathrm{~g} \cdot \mathrm{L}^{-1}$ \\
Freundlich & $\mathrm{y}=3.4466 \mathrm{x}-8.2417$ & 0.7414 & $\mathrm{n}=0.29$ & $\mathrm{~K}_{\mathrm{F}}\left(\mathrm{mg}^{1-(1 / \mathrm{n})} \cdot \mathrm{L}^{1 / \mathrm{n}} \cdot \mathrm{g}^{-1}\right)=5.73 .10^{-9}$ \\
\hline
\end{tabular}

The Freundlich model better describes our experimental results because the value of its correlation coefficient $\left(\mathrm{R}^{2}\right)$ was closer to unity. The adsorption sites therefore increased with adsorption, which implies multilayer adsorption. The maximum adsorption capacity was about $14.4 \mathrm{mg} \cdot \mathrm{g}^{-1}$ and then Since $\mathrm{n}<1$ therefore the adsorption is chemical (Table 3 ).

\subsubsection{Evaluation of the Adsorption Capacity of Methylene Blue on Activated Carbon}

\section{i. Study of Some Parameters Influencing Adsorption}

1. Mass effect of activated carbon on adsorption capacity

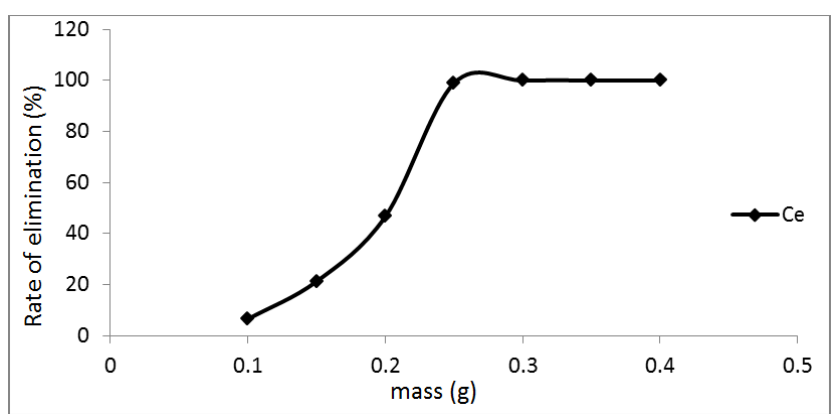

Figure 16. Evolution of the MB Elimination Rate According to the Mass of the $A C$.

Operating conditions: Temperature $=25^{\circ} \mathrm{C}$, stirring speed $=200 \mathrm{rpm}$ and mass $=0.25 \mathrm{~g}$.

Figure 16 showed that the percentage of elimination increases with the mass of activated carbon. The maximum removal rate recorded is of the order of $100 \%$ for a mass $\geq 0.25$ g. The increase in the mass of activated carbon increases the specific surface area and hence the number of adsorption sites, hence the increase in the amount of adsorbed dye [19]. Otherwise, the constancy in the rate of removal of the dye by activated carbon for a mass greater than 0.25 gram is due to the high elimination rate which is close to $100 \%$, so the variation is no longer noticed.

\section{Adsorption kinetics}

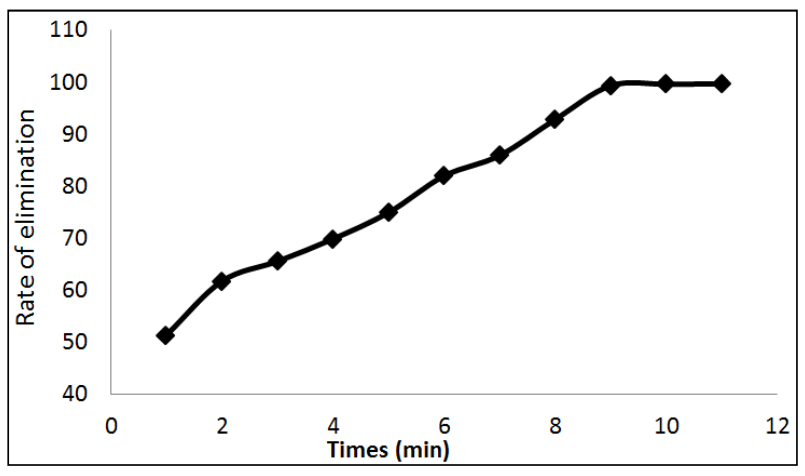

Figure 17. Kinetics of adsorption of the BM on the AC.

Operating conditions: Temperature $=25^{\circ} \mathrm{C}$, stirring speed $=200 \mathrm{rpm}, \mathrm{C}=$ $100 \mathrm{ppm}$ and mass $=0.25 \mathrm{~g}$.

The equilibrium was reached after 10 min with a removal rate which is of the order of $100 \%$ (Figure 17 ). We noted the rapidity of adsorption during the first 5 minutes $(60 \%$ of elimination), this can be interpreted by the fact that, at the beginning of adsorption, the number of active sites available on the surface of the adsorbent was greater than that of the remaining sites After 5 minutes [24].

\section{ii. Modeling of Adsorption Kinetics}

1. Pseudo first order (PPO) and pseudo-second order (PSO)

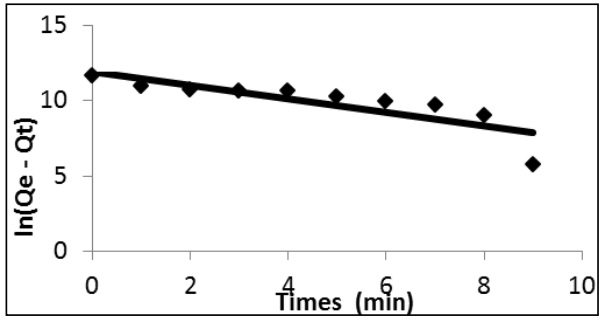

Figure 18. Kinetics Pseudo First-order. 


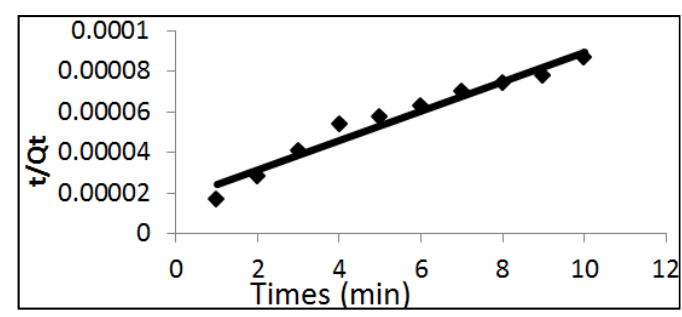

Figure 19. Kinetics Pseudo Second-order.

Table 4. Characteristics of the Different Models.

\begin{tabular}{|c|c|c|c|}
\hline & \multicolumn{3}{|c|}{ Lagergren first order pseudo reaction } \\
\hline Equation & $\mathbf{R}^{2}$ & $K_{1}\left(\min ^{-1}\right)$ & $Q_{\mathrm{e}}(\mathrm{mg} / \mathrm{g})$ \\
\hline$y=-0.4499 x+11.943$ & 0.6997 & 0.4499 & 15373.211 \\
\hline & \multicolumn{3}{|c|}{ Second-order pseudo-reaction of Lagergren } \\
\hline Equation & $\mathbf{R}^{2}$ & $K_{2}$ (g/mg.min) & $Q_{\mathrm{e}}(\mathrm{mg} / \mathrm{g})$ \\
\hline$y=7 E-06 x+2 E-05$ & 0.9584 & 0.0223 & 7.5916 \\
\hline
\end{tabular}

The pseudo-second order model is the one that best describes the adsorption process because the value of its correlation coefficient $\left(\mathrm{R}^{2}\right)$ is closer to 1 (Table 4$)$.

2. Type of broadcasting

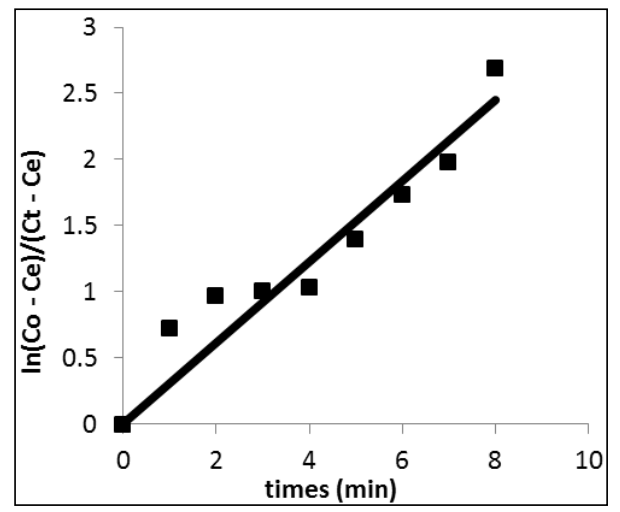

Figure 20. External diffusion model

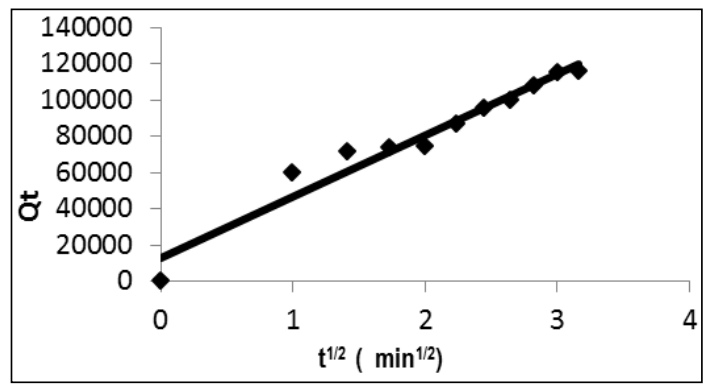

Figure 21. Intraparticular Diffusion Model.

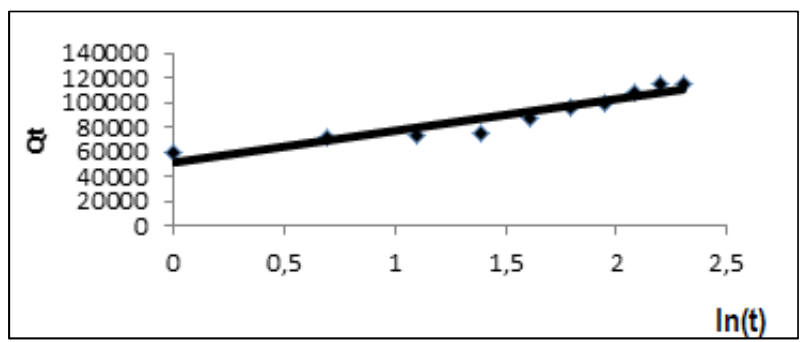

Figure 22. Elovich Model.
Table 5. Characteristics of the Different Models.

\begin{tabular}{|c|c|c|c|}
\hline \multirow{2}{*}{ Equation } & \multicolumn{3}{|c|}{ external diffusion } \\
\hline & \multirow{2}{*}{$\mathbf{R}^{2}$} & \multicolumn{2}{|l|}{$\mathbf{K}_{3}$} \\
\hline$y=0.3066 x$ & & \multicolumn{2}{|c|}{0.3066} \\
\hline \multicolumn{4}{|c|}{ intraparticular diffusion } \\
\hline & $\mathbf{R}^{2}$ & $\mathbf{K}_{4}$ & Constant \\
\hline$y=33743 x+12891$ & 0.9524 & 33743 & 12891 \\
\hline \multicolumn{4}{|l|}{ Model of Elovich } \\
\hline & $\mathbf{R}^{2}$ & $\alpha$ & $\beta$ \\
\hline$y=25427 x+51588$ & 0.8871 & 193384,1362 & $3,9328.10^{-5}$ \\
\hline
\end{tabular}

The adsorption of methylene blue on activated carbon therefore followed an intraparticular model because its correlation coefficient was higher (Table 5).

\section{iii. Modeling of Adsorption Isotherms}

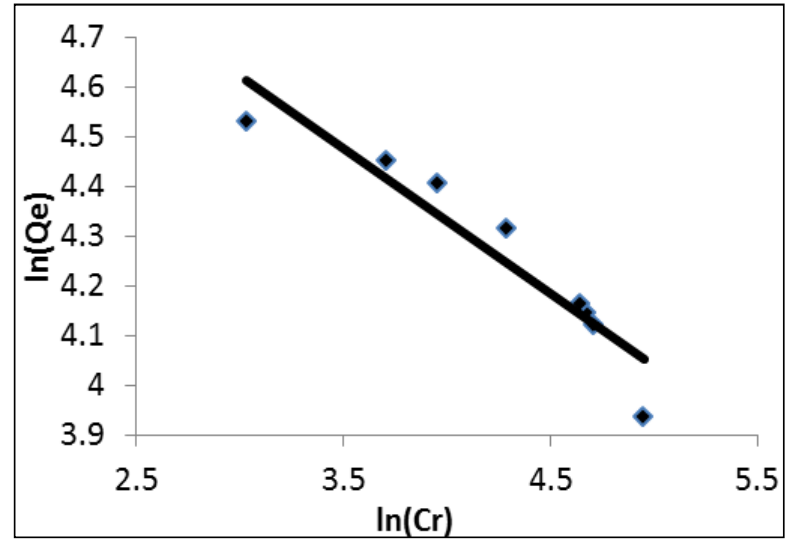

Figure 23. Linear Model of Freundlich.

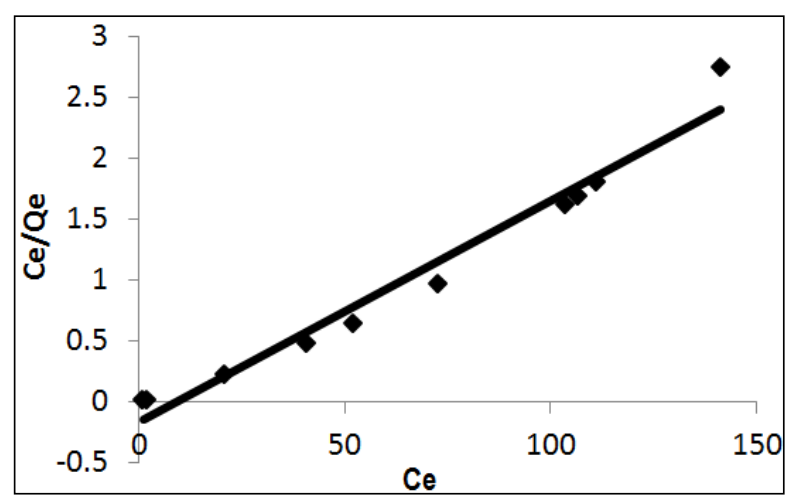

Figure 24. Linear Model of Langmuir.

Table 6. Characteristics of the Different Models.

\begin{tabular}{lllll}
\hline Langmuir & $\mathbf{R}^{2}$ & $\mathbf{Q}_{\max }$ & $\mathbf{k}_{\mathbf{L}}\left(\mathbf{g} . \mathbf{L}^{-1}\right)$ & $\mathbf{R}_{\mathbf{L}}$ \\
\hline & 0.9657 & $55 \mathrm{mg} / \mathrm{g}$ & -0.11 & -0.10 \\
\hline Freundlich & $\mathbf{R}^{2}$ & $\mathbf{k}_{\mathbf{F}}\left(\mathbf{m g}^{\mathbf{1 - ( 1 / \mathbf { n } )}} \cdot \mathbf{L}^{\mathbf{1 / n}} \cdot \mathbf{g}^{-1}\right)$ & $\mathbf{n}_{\mathbf{F}}$ \\
\hline & 0.8903 & 110.39 & -9.21 \\
\hline
\end{tabular}

We found that the Langmuir linear model was the most credible model that best described our experimental results, with $\mathrm{R}^{2}=0.9657$ (Table 6). This shows that the surfaces of 
our activated carbon are homogeneous in terms of energy and promotes monolayer adsorption. The maximum adsorption capacity was about $55 \mathrm{mg} . \mathrm{g}^{-1}$ and then as $\mathrm{n}<1$ therefore the adsorption was chemical (Table 6).

\section{Conclusion}

The aim of this work was to evaluate the adsorption capacity of two adsorbents from the lignocellulosic residues of Lophira Lanceolata. The material consisted of the hulls of Lophira Lanceolata, which were rejected in large quantities after extraction of the oil from the fruits. From this material, charcoal was prepared by carbonization at $400^{\circ} \mathrm{C}$ and activated viachemical activation with orthophosphoric acid diluted to $50 \%$. The result obtained from the iodine test showed that the activeted carbon possessed good microporosity. Adsorption tests made it possible to note that the activated carbon was more effective in the removal of methylene blue than the residues of raw hulls. The removal capacities of methylene blue are governed by pseudo second order adsorption speeds. Adsorption isotherms, such as the Langmuir model and the Freundlich model, simulated the adsorption of methylene blue, respectively, on activated carbon and on raw hulls. The $\mathrm{n}_{\mathrm{F}}$ constant of the Freundlich model was less than 1, which makes it possible to say that the adsorption is chemical. Thus, the hull of Lophira Lanceolata can be used for the removal of methylene blue in aqueous medium and as a precursor of activated carbon. The activated carbon produced from the hulls of Lophira Lanceolata is prioritly usable for the removal of the micropollutants (fluoride ions, nitrate ions, phenol, etc.) from the water.

\section{References}

[1] Ali M., Sreekrishnan T. R. Aquatic toxicity from pulp and paper mill effluents, Adv. Environ. Res, 5 (2): 175196 (2001).

[2] Crini, Gregorio. Non-conventional low-cost adsorbents for dye removal: a review. Bioresource technology, 97 (9): 1061-1085 (2006).

[3] Crini, Grégorio. (2005). Recent developments in polysaccharide-based materials used as adsorbents in wastewater treatment. Progress in polymer science, 30 (1): 38-70.

[4] Nonviho G. Valorisation chimique de la biomasse oléagineuse d'origine béninoise: Lophira Lanceolata et Carapa procera. Thèse de doctorat en chimie. Université d'Abomey-Calavi, 196 (2015).

[5] Balogoun C. K., Bawa M. L., Osseni S., et al. Préparation des charbons actifs par voie chimique à l'acide phosphorique à base de coque de noix de coco. International Journal of Biological and Chemical Sciences, 9(1): 563-580 (2015).

[6] ASTM, D. 4607-94. Standard test method for determination of iodine number of activated carbon (2006).
[7] Benamroui, Faouzia. Élimination des colorants cationiques par des charbons actifs synthétisés à partir des résidus de l'agriculture. Thèse de doctorat (2015). Freundlich, H. The uptake of substances on solid surfaces. Physics Chemical Society, 40:1361-1368 (1906).

[8] M Ghaedi, A Hassanzadeh, Multiwalled carbon nanotubes as adsorbents for the kinetic and equilibrium study of the removal of alizarin red $\mathrm{S}$ and morin. Journal of Chemical (2011).

[9] Belaid, Kumar et Kacha, Smaïl. Etude cinétique et thermodynamique de l'adsorption d'un colorant basique sur la sciure de bois. Revue des sciences de l'eau/Journal of Water Science, 24(2): 131-144 (2011).

[10] Belaid, Kumar Djamel et Kacha, Smail. Étude des cinétiques et des isothermes d'adsorption des colorants de l'industrie textile sur différents adsorbants. Thèse de doctorat (2012).

[11] Joseph O. Etude du potentiel d'utilisation de résidus agricoles haïtiens pour le traitement par biosorption d'effluents pollués. École doctorale Chimie de Lyon (2009).

[12] Ma J., Yu F., Zhou L., Jin L., Yang M. X., Luan J. S., Tang Y. H., Fan H. B., Yuan Z. W., Chen J. H. Enhanced adsorption removal of methyl orange and methylene blue from aqueous solution by alkali-activated multiwalled carbon nanotubes. Appl. Mater. Interfaces, 4:5749-5760 (2012).

[13] Weber, Walter J. et Morris, J. Carrell. Kinetics of adsorption on carbon from solution. Journal of the Sanitary Engineering Division, 89(2): 31-60 (1963).

[14] Lva L., Hea J., Min Wei, Evansa D. G. Yue Duana. Uptake of chloride ion from aqueous solution by calcined layered double hydroxides: Equilibrium and kinetic studies. Water Research, 40:735-743 (2006).

[15] HO, Yuh-Shan et Mckay, Gordon. Sorption of dye from aqueous solution by peat. Chemical engineering journal 70(2): 115-124 (1998).

[16] Langmuir. The adsorption of gases on plane surfaces of glass, mica and platinum. J. Am. Chem. Soc., 40:13611403 (1918).

[17] Freundlich, H. The uptake of substances on solid surfaces. Physics Chemical Society, 40:1361-1368 (1906).

[18] Zhao, Xiao-Liang, Wang, Wen-An, TAN, Jiang-Xiu, et al. Expression of $\beta$-amyloid induced age-dependent presynaptic and axonal changes in Drosophila. Journal of Neuroscience, 30(4):1512-1522 (2010).

[19] DIN, AT Mohd et HAMEED, Bassim H. Adsorption of methyl violet dye on acid modified activated carbon: isotherms and thermodynamics. Journal of Applied Sciences in Environmental Sanitation, 5(2): 161-170 (2010).

[20] Mane, Venkat S., Mall, Indra Deo, et Srivastava, Vimal Chandra. Kinetic and equilibrium isotherm studies for the adsorptive removal of Brilliant Green dye from aqueous solution by rice husk ash. Journal of Environmental M: 2007 anagement, 84(4):390-400 (2007). 
[21] Hui, Pan, Crowcroft, Jon, et Yoneki, Eiko. Bubble rap: Social-based forwarding in delay-tolerant networks. IEEE Transactions on Mobile Computing, 10 (11): 1576-1589 (2011).

[22] Sahnoun, Souleymen, Djermoune, El-Hadi, Soussen, Charles, et al. Analyse modale bidimensionnelle par approximation parcimonieuse et multirésolution. In: XXIIIe Colloque GRETSI Traitement du Signal \& des Images, GRETSI 2011. 2011. p. CDROM.
[23] Özacar, Mahmut. Phosphate adsorption characteristics of alunite to be used as a cement additive. Cement and Concrete Research, 33(10): 1583-1587 (2003).

[24] Karakaya, Mevlüt Maliyet muhasebesi. Enflasyon muhasebesi uygulamall, yeni gelişmelerle bütünleştirilmiş. Gazi kitabevi. (2006). 